\title{
Solitary craniocerebral plasmacytoma mimicking a meningioma
}

\author{
Olarinoye-Akorede $\mathrm{SA}^{1}$, Jimoh $\mathrm{AO}^{2}, \mathrm{Chom} \mathrm{ND}^{1}$, Akano $\mathrm{AO}^{3}$, Hamidu $\mathrm{AU}^{1}$, Abdullahi $\mathrm{K}^{4}$ \\ 1. Department of Radiology, Ahmadu Bello University Teaching Hospital, Shika/Zaria. 2. Division of Neurosurgery, \\ Department of Surgery, Ahmadu Bello University Teaching Hospital, Shika/Zaria. 3. Department of Radiology, National \\ Hospital, Abuja. 4. Department of Pathology, Ahmadu Bello University Teaching Hospital, Shika/Zaria.
}

Correspondence: Olarinoye-Akorede SA. Address: Department of Radiology, Ahmadu Bello University Teaching Hospital, Shika/Zaria. Telephone: 24-803-312-9329. Email: bankesakorede@gmail.com

Received: May 13, 2012

DOI : $10.5430 /$ jbgc.v2n2p110
Accepted: J une 18, 2012

URL: http://dx.doi.org/10.5430/jbgc.v2n2p110

\section{Abstract}

When the skull or the central nervous system is involved in plasma cell dyscrasia, there is usually the presence of the disease elsewhere in the bone or in the soft tissues. Solitary craniocerebral lesion is therefore uncommon. We present below, a case of a forty year old male with complaints of skull swelling of four years duration which was diagnosed to be a solitary plasmacytoma without the systemic disease. The imaging similarity between dural plasmacytoma which occurs as a solitary lesion and a meningioma often causes a diagnostic dilemma and may only be distinguished histologically. Also, appropriate diagnosis is important in order to distinguish this rather benign tumor from its systemic counterpart as their prognoses differ.

\section{Key words}

Solitary, Plasmacytoma, Meningioma

\section{I ntroduction}

Plasmacytomas are neoplastic proliferation of plasma cells which affects the bones and the soft tissues. Solitary craniocerebral plasmacytoma in the absence of plasma cell dyscrasias elsewhere in the body is reportedly rare, with an incidence of less than $1 \%{ }^{[1,2]}$. True solitary plamacytoma is therefore by definition, a plasma cell monoclonal gammopathy that occurs in a single site only, when the disease is not found elsewhere in the body. The craniocerebral lesion can arise from the skull, dura or rarely, the brain. The most common presentation of a dural plasmacytoma is a soft tissue mass which may or may not be painful.

When solitary plasmacytoma affects other bones, it tends to disseminate in later years whereas the cranial lesion has a better prognosis if a strict criteria is employed in making the diagnosis ${ }^{[3]}$.

\section{Case report}

S.A is a forty one year old male banker who was referred for follow up Computed Tomographic (CT) examination on account of a swelling on the left side of his head of about four years duration. This was initially painless but it has been 
progressively increasing in size and now associated with some pain. There was no history of trauma. There was no headache, blurring of vision, vomiting or signs of raised intracranial pressure. There were no symptoms referable to any other systems.

General physical examination showed a healthy young man anicteric not pale and afebrile. He had a huge soft tissue swelling on the left side of his head. The overlying skin was intact. Neurological examination showed no abnormality. The review of the other systems was also normal.

Hematological tests showed normal hemoglobin level and no evidence of infection. The peripheral bone marrow study did not reveal any abnormality. Urine electrophoresis was negative for Bence Jones proteins and serum electrolytes and urea were all within normal limits.

The initial CT examination from the referral centre showed hyperostosis of the left frontal bone (see Figure 1a) as well as a hyperdense enhancing mass in the left fronto parietal region (see Figure 1b). Based on these radiological features, a clinical impression of meningioma was made with differential diagnoses of metastatic skull deposit and multiple myeloma with cranial involvement.

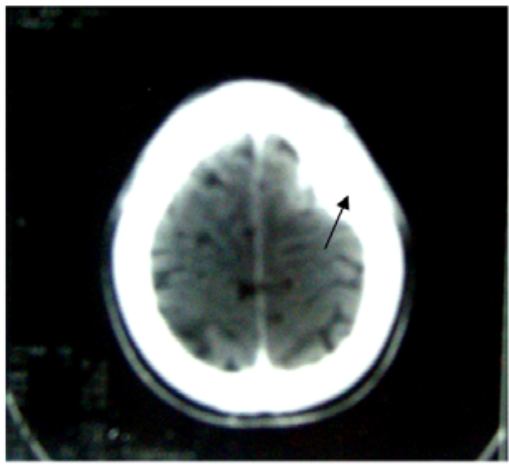

Figla

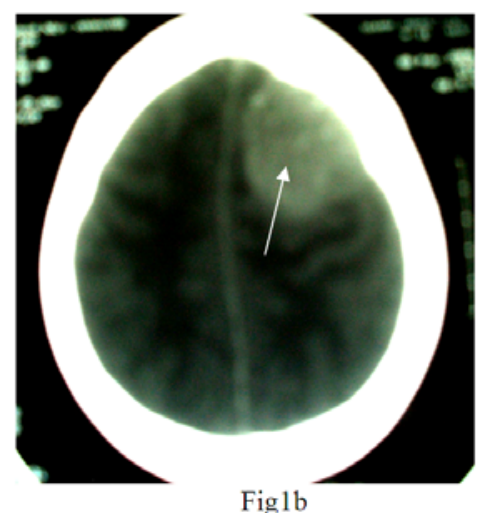

Fig1b

Figure 1. a. Axial CT image near the skull vertex showing hyperostosis of the left fronto parietal bone (black arrow). b. A hyperdense mass adjacent the inner table in the left fronto parietal region(white arrow).

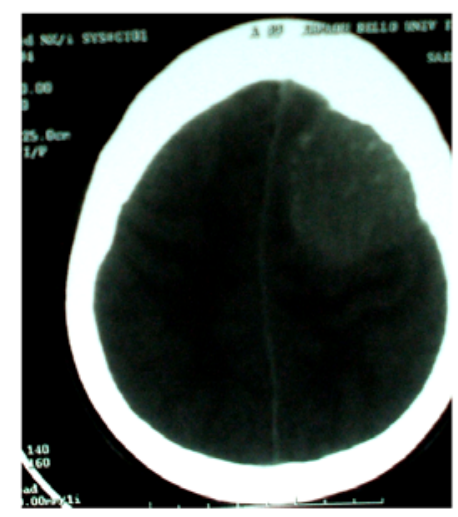

Fig 2a

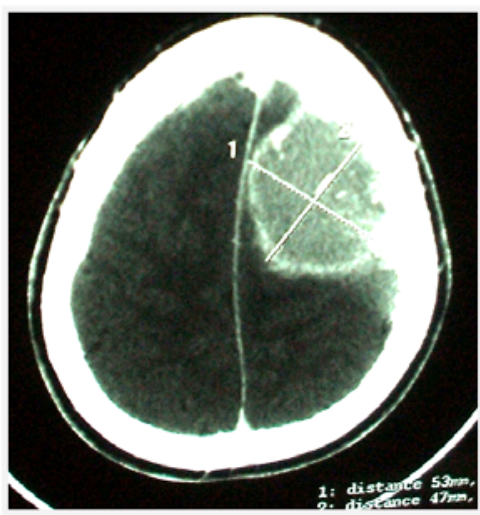

Fig $2 \mathrm{~b}$

Figure 2. a. Non contrast and $2 \mathrm{~b}$ contrast enhanced Axial CT images showing an enhancing hyperdense mass adjacent to the inner skull table in the left parietal region. Associated erosion and irregularity of the inner table is also noted. 
The follow up CT images two years later at our hospital showed this hyperdense and enhancing mass adjacent to the dura in the left parietal area (see Figures 2a and 2b). Extensive ipsilateral lytic bony destruction and overlying soft tissue swelling was also seen (see Figures 3 and 4). There was no infiltration of the underlying brain parenchyma. The ventricular systems and the basal cisterns showed no abnormality. The patient was evaluated over a two week period and subsequently had surgery four months later. This revealed a soft tissue mass measuring $8 \mathrm{~cm}$ in length, $6 \mathrm{~cm}$ in depth and $8 \mathrm{~cm}$ wide which was infiltrating the dura. The brain parenchyma itself was however intact.

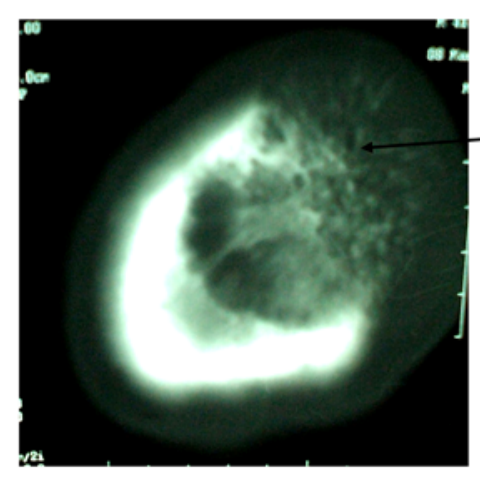

Fig.3a

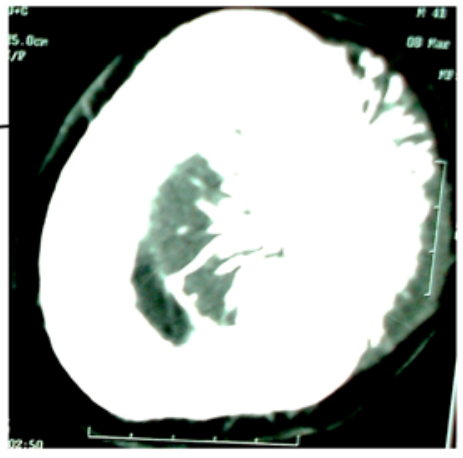

Fig. $3 \mathrm{~b}$

Figure 3. Bone window and contrast enhanced images showing a huge overlying soft tissue swelling with extensive lytic bony destruction.

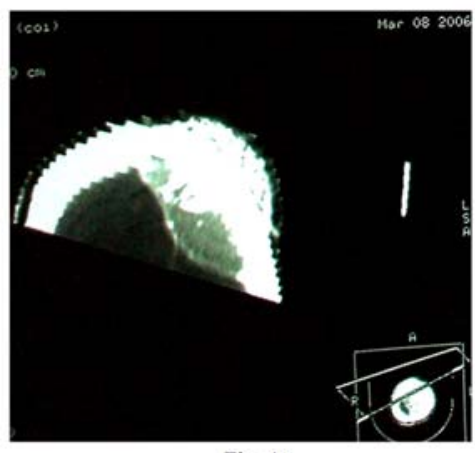

Fig. $4 \mathrm{a}$

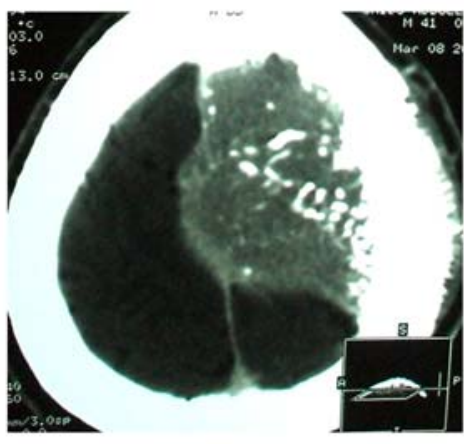

Fig. $4 \mathrm{~b}$

Figure 4. shows the mass to be dural based and crosses the midline to the right side
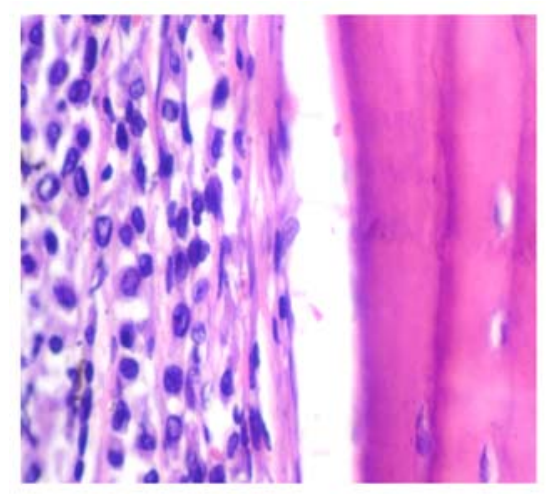

Figure 5. Section from tumor specimen showing sheets of dysplastic plasma cells and a few spindly fibroblasts 
The final histologic diagnosis was a dural plasmacytoma (see Figure 5). The patient has been on follow up at the surgical outpatient department for six years since surgery and there is no evidence of systemic dissemination.

\section{Discussion}

Plasmacytomas can be classified as either multiple or solitary. The solitary lesions are divided into the osseous type; and the extra osseous or extramedulary type (SEP) while the osseous type is further divided into solitary plasmacytoma of bone (SBP) and solitary plasmacytoma of skull (SPS).

It is important to distinguish between primary solitary craniocerebral plasmacytoma and a craniocerebral lesion which is secondary to multiple myeloma. While multiple myeloma has a poor prognosis and is associated with treatment relapse and resistance, solitary plasmacytoma runs benign course, is radiosensitive and it is a potentially curable ${ }^{[1,3]}$. Solitary plasmacytoma at other bone sites unlike the craniocerebral lesion has a tendency to systemic dissemination after 7 to 23 years ${ }^{[3]}$. When compared with multiple myeloma, both tumors show similar histologic features. However, they differ in their clinical presentation and radiologic findings. Thus, there exists a relationship between this tumor and multiple myeloma, the nature of which is still unsure. To some authors, it is a separate disease entity ${ }^{[4]}$, while some consider it to be part of the same disease spectrum ${ }^{[5,6]}$ because of its unpredictabile ability of either remaining solitary or to disseminate. However, when the solitary plasmacytoma of bone becomes disseminated, it becomes strikingly similar to multiple myeloma in appearance, predilection site and multiplicity.

The parietal region is the most commonly affected site ${ }^{[7]}$, as was seen in this case. Outside the skull, the dura is the next site affected. Lesions within the brain parenchyma are very rare. As found in this patient, there is a male preponderance, compatible with previously reported male / female ratio of 2:17.

In making a diagnosis of a true primary solitary plasmacytoma, a strict criteria is employed which include: a radiological solitary lesion, histologic confirmation, negative bone marrow examination, negative immune electrophoresis, negative urine test for Bence Jones protein, no evidence of hyperglobulinemia ${ }^{[8,9]}$. In addition, there should be no radiological or laboratory evidence of systemic dissemination for two years following initial diagnosis ${ }^{[10]}$. All of these criteria were met in this patient.

The etiology of the soft tissue (extramedullary) counterpart has been suggested by Wiltshaw ${ }^{[11]}$ to be due to chronic stimulation by irritants and viral infection, while the etiology of the bone lesion has not been attributable to any cause.

Plain skull $\mathrm{X}$ ray is usually one of the initial radiologic requests. The findings are those of a lytic bone lesion with clear margins and a narrow zone of transition. Rarely, it could present as expansile, soap bubbly appearance resembling an aneurismal bone cyst as has been described by Huvos et al. ${ }^{[12]}$. In this patient however, the finding was that of hyperostosis, resembling a meningioma.

Calvarial lesion on Computed tomographic (CT) appears as a lytic expansile hyperdense lesion which may involve both skull tables while the dural lesion compresses the adjacent brain. Occasionally tumoral calcifications may be seen. Homogenous enhancement occurs with intravenous contrast medium.

On magnetic resonanace imaging (MRI), tumors are isointense on TI weighted and iso -to hyperintense on T2 weighted images. It also shows homogenous contrast enhancement. Intradural solitary plasmscytomas are strikingly similar to meningiomas as both lesions commonly occur in women in mid and late life. They affect similar sites that is, cerebral convexities, falx, tentorium, and sphenoid ridge and they have similar CT and MRI features. Differentiation is therefore based on histology. This patient was however a male, in his fourties. In deed solitary cranio-cerebral plasmacytoma presenting as meningioma in a male is rarely reported, making this patient a unique case 
Plasma cell granuloma, which is inflammatory in origin, can only be differentiated from solitary plasmacytoma histologically.

Carotid angiography has a limited role to play although it provides vascular road map before surgery and it typically shows dense tumor stain from branches supplied by the external carotid artery.

The treatment of choice is surgical excision with or without radiotherapy. This patient was management with both. Some authors advocate radiotherapy only, since the tumor is radiosensitive.

Although the prognosis is good in the absence of systemic disease, regular lifelong follow up is required, as is being done for this patient. This is because the possibility of dissemination of the disease cannot be completely ruled out.

\section{Summary}

A rare case of solitary dural plasmacytoma has been presented. Its clinical presentation, radiologic findings and literature review discussed.

\section{References}

[1] Kirmuluz A, Weiss HD, Jiji VH, Kirsch MB. Solitary intracranial plasmacytoma: two patients with extended follow up. Am Neurol. 1982; 11: 529-532. PMid:7103430 http://dx.doi.org/10.1002/ana.410110514

[2] Pasqualetti P, Festuccia V, Collacciani A, Casale R. The natural history of monoclonal gammopathy of undetermined significance. A 5 to 20-year follow-up of 263 cases. Acta Haematol. 1997; 97(3): 174-179. PMid:9066713 http://dx.doi.org/10.1159/000203676

[3] Matsuda M, Nakazawa T, Kizuki H, Matsumura K, Nakasu S, Handa J. Solitary of the skull vault: case report. Neurol Med Chir (Tokyo). 1996; 36: 388-392. PMid:8700317 http://dx.doi.org/10.2176/nmc.36.388

[4] Bindal AK, Bindal RK, Van Loveren H, Sawaya R. Management of intracranial plasmacytoma. J Neurosurg. 1995; 83: $218-221$. PMid:7616264 http://dx.doi.org/10.3171/jns.1995.83.2.0218

[5] Clarke E. Cranial and intracranial myelomas. Brain. 1954; 77: 61-81. PMid:13160259 http://dx.doi.org/10.1093/brain/77.1.61

[6] Tong D, Griffin TW, Laramore GE, Kurtz MJ, Russell AH, Groudine MT et al. Solitary plasmacytoma of bone and soft tissues. Radiology. 1980; 135: 195-198. PMid:7360960

[7] Provenzale MJ, Schaefer SP, Traweek T, Ferry J, Moore OJ, Freidman AH, McLendon RE. Craniocerebral plasmacytoma: MR Features. AJNR. 1997; 18: 389- 392. PMid:9111682

[8] Barone CM, Jimenez DF, Argamasco RV. Solitary calvarial palsmacytoma. J Craniomaxillofac Surg. 1992; 3: 108-112.

[9] Miyazawa N, Kurihara H, Kaneko M, Yamazaki H, Wakao T, Nukui H. Multiple myeloma manifesting as a solitary cranial tumor. Case report. Neurol Med Chir (Tokyo). 1989; 29: 917-921. PMid:2482942 http://dx.doi.org/10.2176/nmc.29.917

[10] Christopherson WM, Miller AJ. A re-evaluation of solitary plasma cell myeloma of bone. Cancer. 1950; 3: $240-252$. http://dx.doi.org/10.1002/1097-0142(1950)3:2<240::AID-CNCR2820030206>3.0.CO;2-H

[11] Wiltshaw E. The natural history of extramedullary plasmacytoma and its relation to solitary myeloma of bone and myelomatosis. Medicine (Baltimore). 1976 May; 55(3): 217-238. PMid:1272069 http://dx.doi.org/10.1097/00005792-197605000-00002

[12] Huvos AG: Multiple myeloma including solitary osseous myeloma. In: Bone Tumors: Diagnosis, Treatment, and Prognosis. Philadelphia, Pa: WB Saunders Co. 1992; 653-667. 